\title{
Conceptual Design of a Small Hybrid Unmanned Aircraft System
}

\author{
Umberto Papa, ${ }^{1}$ Salvatore Ponte, ${ }^{2}$ and Giuseppe Del Core ${ }^{1}$ \\ ${ }^{1}$ Department of Science and Technology, University of Naples "Parthenope", Naples, Italy \\ ${ }^{2}$ Department of Industrial and Information Engineering, University of Campania "Luigi Vanvitelli", Aversa, Italy
}

Correspondence should be addressed to Umberto Papa; umberto.papa@uniparthenope.it

Received 3 November 2016; Revised 18 April 2017; Accepted 7 May 2017; Published 30 May 2017

Academic Editor: Guizhen Yu

Copyright (C) 2017 Umberto Papa et al. This is an open access article distributed under the Creative Commons Attribution License, which permits unrestricted use, distribution, and reproduction in any medium, provided the original work is properly cited.

\begin{abstract}
UAS (Unmanned Aircraft System) technologies are today extremely required in various fields of interest, from military to civil (search and rescue, environmental surveillance and monitoring, and entertainment). Besides safety and legislative issues, the main obstacle to civilian applications of UAS systems is the short time of flight (endurance), which depends on the equipped power system (battery pack) and the flight mission (low/high speed or altitude). Long flight duration is fundamental, especially with tasks that require hovering capability (e.g., river flow monitoring, earthquakes, devastated areas, city traffic monitoring, and archeological sites inspection). This work presents the conceptual design of a Hybrid Unmanned Aircraft System (HUAS), merging a commercial off-the-shelf quadrotor and a balloon in order to obtain a good compromise between endurance and weight. The mathematical models for weights estimation and balloon static performance analysis are presented, together with experimental results in different testing scenarios and complex environments, which show 50\% improvement of the flight duration.
\end{abstract}

\section{Introduction}

Unmanned Aircraft Systems (UAS) play an important role in various military and civil applications, particularly for monitoring and surveillance of areas (urban traffic, coast guard patrolling, border patrolling, detection of illegal imports, archeological site prospection, etc.), climate research (weather forecast, river flow), agricultural studies, air composition and pollution studies, inspection of electrical power lines, monitoring gas or oil pipe lines, entertainment, and TV: their diffusion is mainly due to the capacity to perform dangerous, sensitive, environmentally critical, or dull tasks with low costs and increased manoeuvrability and survivability. Most civilian UAS missions require flying speeds lower than $50 \mathrm{kts}(70 \mathrm{~km} / \mathrm{hr})$ at low altitudes, with hovering capability to perform close proximity inspection (e.g., air quality measurements at high spatial resolution [1], powerline inspection, subsurface geology and agriculture [2], mineral resource analysis, or incident control by police and fire services) [3-5]. Some missions also require significant flight duration time. Increasing endurance generally implies additional costs in terms of fuel consumption and airframe complexity, resulting in reduced efficiency of payload and/or reduced range for size, mass, and financial cost.

Currently, a broad range of UAS exists, from small and lightweight fixed-wing aircrafts to rotor helicopters, largewingspan airplanes, and quadcopters, generally providing persistence beyond the capabilities of manned vehicles [6]. Table 1 [7] classifies UAS with respect to mass, range, flight altitude, and endurance.

VTOL (Vertical Take-Off and Landing) aircrafts provide many advantages with respect to Conventional Take-Off and Landing (CTOL) vehicles, first of all the capability of hovering and the small area required for take-off and landing. Among VTOL aircrafts, such as conventional helicopters and crafts with rotors like the tilt-rotor and fixed-wing aircrafts with directed jet thrust capability, the quadrotor or quadcopter is often preferred, especially in the academic research on mini- or microsize UAS. Quadrotors are a good alternative to conventional rotorcrafts, due to their ability to hover and move without the complex systems of linkages and blade elements typical of a standard single-rotor vehicle [5] [8, Ch. 1]. By employing four rotors to generate differential thrust, the quadrotor gains flexibility, swift manoeuvrability, and 
TABLE 1: Extract of UAV categories defined by UVS International (Unmanned Vehicle Systems Association). Figures on category name "mini" depend on different countries.

\begin{tabular}{lcccc}
\hline Category name & $\begin{array}{c}\text { Mass } \\
{[\mathrm{kg}]}\end{array}$ & $\begin{array}{c}\text { Range } \\
{[\mathrm{km}]}\end{array}$ & $\begin{array}{c}\text { Flight } \\
\text { altitude }[\mathrm{m}]\end{array}$ & $\begin{array}{c}\text { Endurance } \\
{[\text { hours }]}\end{array}$ \\
\hline Micro & $<5$ & $<10$ & 250 & 1 \\
Mini & $<25 / 30 / 150$ & $<10$ & $150 / 250 / 300$ & $<2$ \\
Close range & $25-250$ & $10-30$ & 3000 & $2-4$ \\
$\begin{array}{l}\text { Medium range } \\
\text { High altitude, }\end{array}$ & $50-250$ & $30-70$ & 3000 & $3-6$ \\
long range & $>250$ & $>70$ & $>3000$ & $>6$ \\
\hline
\end{tabular}

TABLE 2: Comparison among different VTOL concepts and design issues (see text for explanation).

\begin{tabular}{lcccccccc}
\hline Design driver & $\mathrm{A}$ & $\mathrm{B}$ & $\mathrm{C}$ & $\mathrm{D}$ & $\mathrm{E}$ & $\mathrm{F}$ & $\mathrm{G}$ & $\mathrm{H}$ \\
\hline Mechanics simplicity & 1 & 1 & 1 & 1 & 3 & 4 & 3 & 4 \\
$\begin{array}{l}\text { Aerodynamics } \\
\text { complexity }\end{array}$ & 1 & 1 & 1 & 1 & 1 & 3 & 1 & 4 \\
Low-speed flight & 2 & 4 & 3 & 2 & 3 & 4 & 4 & 4 \\
Stationary flight & 1 & 4 & 4 & 2 & 4 & 3 & 4 & 4 \\
Control cost & 2 & 1 & 2 & 1 & 1 & 3 & 4 & 3 \\
Payload/volume & 2 & 2 & 3 & 1 & 2 & 1 & 4 & 3 \\
Maneuverability & 3 & 4 & 3 & 3 & 2 & 1 & 2 & 3 \\
High-speed flight & 3 & 2 & 2 & 3 & 4 & 1 & 1 & 3 \\
Miniaturization & 2 & 2 & 2 & 4 & 3 & 1 & 4 & 3 \\
Power cost & 3 & 2 & 2 & 3 & 2 & 4 & 2 & 1 \\
Survivability/Endurance & 2 & 1 & 1 & 3 & 3 & 3 & 3 & 1 \\
Total quality index & 22 & 24 & 24 & 24 & 28 & 28 & 32 & 33 \\
\hline
\end{tabular}

increased payload. Table 2, adapted from [5], gives quality indexes (from $1=$ bad to $4=$ very good) for some design issues pertaining to different VTOL vehicle concepts, namely, birdlike (A), single-rotor (B), tandem rotors (C), insect-like (D), axial rotor $(\mathrm{E})$, blimp $(\mathrm{F})$, coaxial rotors $(\mathrm{G})$, and quadrotor $(\mathrm{H})$.

The quadrotor has good ranking among VTOL vehicles, but it still keeps some drawbacks. For example, the craft size is rather large; the energy consumption is great; therefore the flight time is short, the control algorithms are very complex, as only four actuators have to control the six degrees of freedom (DOF) of the craft (a quadrotor is a typical example of an underactuated system), and the changing aerodynamic interference patterns between the rotors have to be taken into account [5, Chap. 3] [8, Parts I and II].

Endurance is a fundamental task in UAS design. Generally, it depends on the payload and the aircraft mission (search and rescue, inspection tasks, etc.). Typical UAS endurances are in the range from $30 \mathrm{~min}$ (micro UAS) to 24 hours (high altitude, long endurance, or HALE, vehicles). Table 3 classifies UAS in terms of mass, range, flight altitude, and endurance.

Extended flight duration has been mainly addressed by means of optimization of the electric propulsion system $[9,10]$, use of hybrid-electric systems [11], investigation on innovative power sources $[12,13]$, use of solar-powered

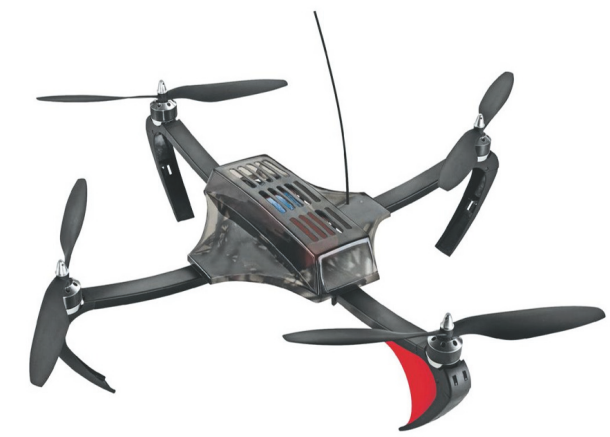

FIgURE 1: The adopted small quadrotor (Conrad 450 ARF $35 \mathrm{Mhz}$ ).

HALE [14], or use of a variable pitch propeller [15]. This work proposes an alternative approach to improve endurance of a nonexpensive (micro-UAV), commercial quadrotor, by applying a balloon to reduce weight and power consumption.

Little research is available in the literature in the field of low-altitude, low-speed UAVs equipped with balloons, except for some work related to subsurface geology detection with a hybrid UAV equipped with an airbag [16]. Our approach aims for a multimission platform with dedicated payload, suitable for a broad range of applications in the fields of Simultaneous Localization and Mapping (SLAM), exploration, search and rescue, remote sensing, and environmental monitoring.

The mini quadrotor used for our investigations is the Conrad Quadrocopter 450 ARF [17], shown in Figure 1.

The quadrotor is equipped with a payload composed of a Global Positioning System (GPS) receiver module, an Inertial Measurement Unit (IMU), a sonar altimeter, a small camera module, and main microcontroller hardware (Arduino, Raspberry). Such a payload was selected considering a multimission data gathering platform (attitude measurement, GPS data collection, remote sensing, vision-based navigation, etc. [18-20]). Typical endurance of the chosen quadrotor is less than 2 hours (without payload), whereas in our case (motor propeller plus payload) the flight time has found to be less than 1 hour [18]. Balloons are not easily manoeuvrable, but a hybrid solution (quadcopter merging) could effectively exploit the advantages of a quadrotor vehicle (flexibility, welldesigned structure, and security) and the strength points of a balloon (low noise, low energy consumption, and buoyancy providing most of the flight lift), increasing endurance by reducing power consumption $[2,20,21]$.

The preliminary design involves determination of weights, gross static lifting capability of the balloon (i.e., the portion of the balloon's total lift attributable to its buoyancy), lifting gas properties, atmospheric conditions in the flight range, and influence of the balloon size on lift. Although the dynamics and aerodynamics of the HUAS operations must be considered in a complete design of the balloon, we will consider only the balloon static performance, following the approach described in [22].

The paper is structured as follows: in Section 2 we present the HUAS conceptual design. In Section 3 we describe the mathematical models to estimate weight and size of 
TABLE 3: UAS classification based on mass, distance covered, altitude, and flight endurance [5].

\begin{tabular}{|c|c|c|c|c|}
\hline $\begin{array}{l}\text { Category } \\
\text { name }\end{array}$ & $\begin{array}{c}\text { Mass } \\
{[\mathrm{kg}]}\end{array}$ & $\begin{array}{l}\text { Range } \\
{[\mathrm{km}]}\end{array}$ & $\begin{array}{l}\text { Flight } \\
\text { altitude } \\
{[\mathrm{m}]}\end{array}$ & $\begin{array}{c}\text { Endurance } \\
\text { [hours] }\end{array}$ \\
\hline Micro & $<5$ & $<10$ & 250 & 1 \\
\hline Mini & $5-100$ & $<10$ & $150-300$ & $<2$ \\
\hline Close range & $25-250$ & $10-30$ & 3000 & $2-4$ \\
\hline $\begin{array}{l}\text { Medium range } \\
\text { Low endurance }\end{array}$ & $50-250$ & $30-70$ & 3000 & $3-6$ \\
\hline High altitude, long range & $>250$ & $>70$ & $>3000$ & $>6$ \\
\hline $\begin{array}{l}\text { Medium altitude } \\
\text { long endurance } \\
\text { (MALE) }\end{array}$ & $>1000$ & $>100$ & $5000-15000$ & $<24$ \\
\hline $\begin{array}{l}\text { High altitude } \\
\text { long endurance } \\
\text { (HALE) }\end{array}$ & $>10000$ & $>100$ & $>15000$ & $24+$ \\
\hline
\end{tabular}

the inflated balloon and to calculate its static performance, presenting preliminary results in Section 4. In Section 5 we present our conclusions and future research challenges.

\section{HUAS Conceptual Design}

The most interesting improvement created by the HUAS is the aerostatic lift provided by the balloon, which, combined with the fan lift of the propulsion system, allows the vehicle to achieve easy take-off, climbing, hovering, and landing with reduced power consumption. The main issues which inspired us to propose a hybrid solution are as follows:

(1) Effective control of the HUAS flight path by static lift (provided by the balloon) and rotor power: this allows hovering, flying, climbing, and landing at any height, improving flexibility of the mission and enlarging the range of applicability.

(2) Low operating speed, low-altitude missions, operation in discontinues trajectories: the HUAS could be effectively used in high-resolution spatiotemporal sampling applications and in monitoring known environments.

(3) Minimization of complexity of the fuselage structure, drive mechanisms, and engine systems: this implies simpler manufacturing process and shorter production cycle.

(4) Low noise, low vibration, low turbulence generation: the HUAS does not disturb the environment that is being monitored or measured and reduces sensor noise and potential hardware malfunction due to vibration.

(5) Reduced cost of energy and power systems and rapid prototyping: the HUAS is an advanced lowcost system easily viable for potential commercial operators.

A stand-alone balloon is not easily manoeuvrable mainly for its big inertia, but in static conditions it is very reliable.

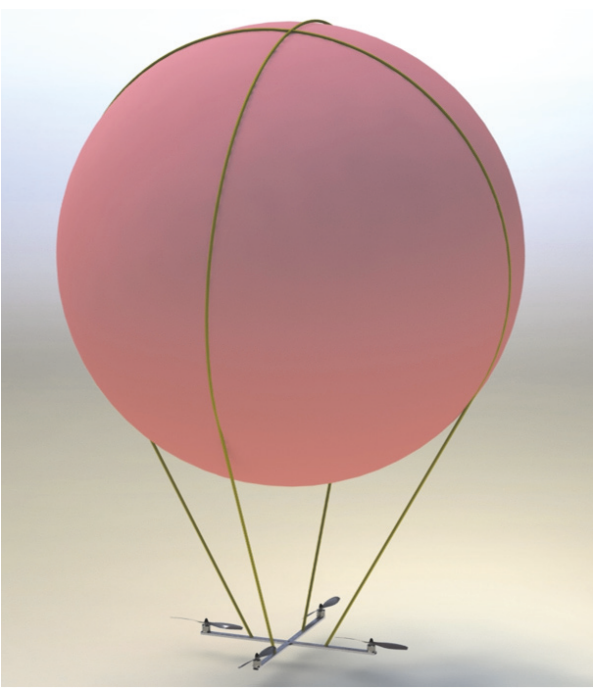

FIGURE 2: HUAS design concept.

It is possible to manage and control the balloon by means of propeller speed changes. Creating hybrid lift (static lift and fan lift) to achieve take-off, hovering, and landing with reduced energy consumption would improve flight duration. The overall system is able to correct any change of flight attitude due to voluntary actions or instability induced by the balloon.

Figures 2 and 3 show the structure of the HUAS, with a basic balloon, support lines, safety lines, and a synthetic model of the quadcopter. The balloon diameter has been chosen to be $1.5 \mathrm{~m}$. Thrust propellers improve manoeuvrability of the HUAS. A simple web frame is chosen to wrap the balloon and link to quadrotor; it is a nonrigid solution, able to keep the two systems linked but independent, each with its own function: the balloon for static gross lift (mainly upward) and the quadrotor for flight control. The buoyancy of the balloon provides most of the flight lift, reducing power consumption and increasing endurance. $3 \mathrm{D}$ CAD software 


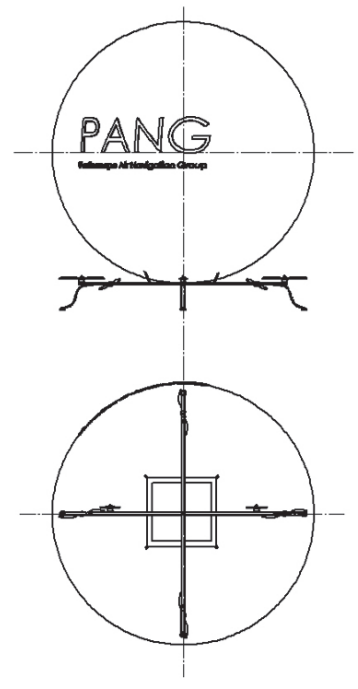

FIgURE 3: HUAS 3D CAD.

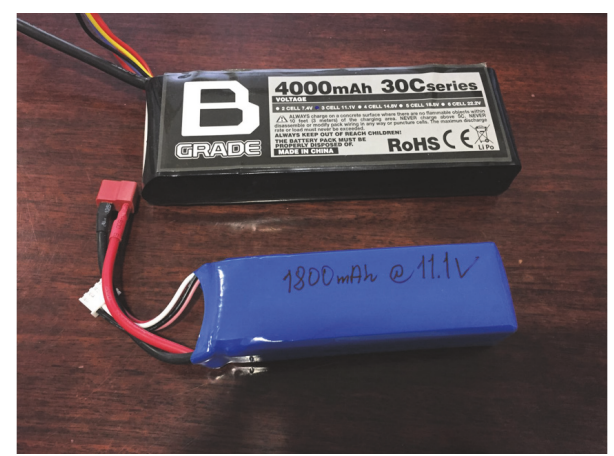

FIGURE 4: LiPo battery packs used in research tests.

was used to make a preliminary structure for successive balloon size validation.

The installed battery packs are lightweight LiPo (Lithium Polymer), with capacities of $1800 \mathrm{mAh}$ and $4000 \mathrm{mAh}$ @11.1 V, respectively (Figure 4).

Endurance in minutes, without the balloon, for a normal mission (take-off, hovering, and landing) is shown in Table 4.

\section{Estimation of Weights and Balloon Sizing}

Each configuration was checked through a static analysis in CAD software, choosing a solution which allowed us to achieve good compromise between weight and lift. The analytical techniques described in [22] were applied, considering three subsystems of the HUAS:

(i) Inflation gas

(ii) Balloon structure

(iii) Quadrotor system

Weight and the static performance of each part were determined separately and successively added. Inertia and
TABLE 4: Endurance for the two LiPo batteries used.

\begin{tabular}{lcc}
\hline $\begin{array}{l}\text { Capacity of } \\
\text { LiPo battery }\end{array}$ & Take-off and landing & Hovering \\
\hline $4000 \mathrm{mAh}$ & $<5 \mathrm{~min}$ & $\approx 40 \mathrm{~min}$ \\
$1800 \mathrm{mAh}$ & $<5 \mathrm{~min}$ & $\approx 15 \mathrm{~min}$ \\
\hline
\end{tabular}

dynamic properties were not considered, postponing their evaluation to future work.

3.1. Take-Off Weight Estimation. For a correct evaluation of the gross static lift provided by the balloon, it is necessary to estimate the HUAS take-off gross weight $\left(W_{\mathrm{TO}}\right)$, which depends on all components of the HUAS (the quadcopter structure, payload, battery pack, support lines, safety lines, tether lines, and the balloon itself).

The net force acting on the balloon tether line equals the gross static lift of the balloon less the constant tare of the bag. Equation (1) gives the gross static lift $L$ of the balloon [22]:

$$
L=\left(\rho_{\text {air }}-\rho_{g}\right) V_{g}
$$

where $V_{g}$ is the volume occupied by the gas when the balloon is fully inflated. In ideal conditions, the gross lift is equal to $W_{\text {TO }}$, given by

$$
W_{\mathrm{TO}}=W_{\mathrm{eq}}+W_{B}+W_{\mathrm{batt}}+W_{p},
$$

where weights are referred to empty quadcopter $W_{\text {eq }}$, balloon (lines, gas, and bag included) $W_{B}$, battery pack $W_{\text {batt }}$, and payload (sensors onboard) $W_{p}$. Obviously, $W_{B}$ depends on the balloon size and is the unknown parameter, whereas the other contributions to $W_{\text {TO }}$ are constant and known. Using a weight coefficient $k_{x}=W_{x} / W_{\text {TO }}$ (with $x$ representing any of the subscripts in the right side of (2)), (2) is rewritten as

$$
k_{\mathrm{eq}}+\frac{W_{B}}{W_{\mathrm{TO}}}+k_{\mathrm{batt}}+k_{p}=1
$$

and derive $W_{\text {TO }}$ as follows:

$$
W_{\mathrm{TO}}=-\frac{W_{B}}{\left(k_{\mathrm{eq}}+k_{\mathrm{batt}}+k_{p}\right)} .
$$

The UAS system considered in this work has a total weight $\left(W_{\text {eq }}+W_{\text {batt }}+W_{p}\right)$ of about $3 \mathrm{~kg}$ : this is, according to Archimedes' law, the buoyancy requirement.

3.2. Balloon Static Performance and Sizing. A classical airship has various configurations: flabby balloon with ballonet (air chamber), partially inflated and fully inflated (Figure 5). It can also be composed of two parts: a hull and a tail fin assembly. In this work, a fully inflated configuration (logging balloon, without tail fin) was chosen.

For safe flight conditions, the gas volume in fully inflated configuration must always be less than or equal to the total volume. Correct sizing must also take into account temperature and pressure influences on the lifting gas, which 
TABLE 5: Lifting gas comparison.

\begin{tabular}{lcc}
\hline Lifting gas & $\begin{array}{c}\text { Density at sea level and } \\
0^{\circ} \mathrm{C}\end{array}$ & $\begin{array}{c}\text { Lifting force of } \\
1 \mathrm{~m}^{3} \text { of gas }\end{array}$ \\
\hline Helium $(\mathrm{He})$ & $0.178 \mathrm{~kg} / \mathrm{m}^{3}$ & $11.8 \mathrm{~N}$ \\
Hydrogen $(\mathrm{H})$ & $0.090 \mathrm{~kg} / \mathrm{m}^{3}$ & $10.9 \mathrm{~N}$ \\
Air & $1.292 \mathrm{~kg} / \mathrm{m}^{3}$ & $\# \#$ \\
\hline
\end{tabular}

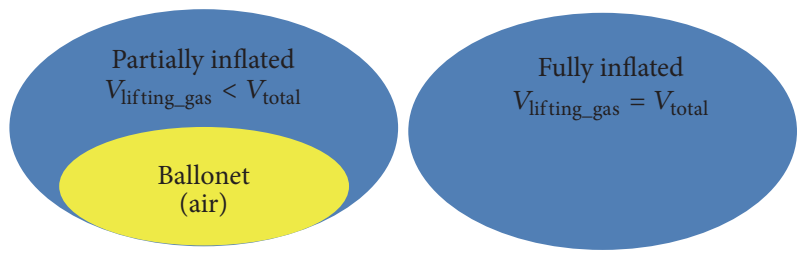

FIGURE 5: Balloon configurations.

obviously must have density lower than air density. Among several available types of lifting gases (hot air, hydrogen, helium, ammonia, etc.), we have chosen helium (He), due to its availability and readiness to use without many control systems (valve, pipes, etc.). Table 5 compares lifting forces of He and hydrogen.

From (1), we consider a lifting force for $1 \mathrm{~m}^{3}$ of gas at sea level and $0^{\circ} \mathrm{C}$. Lift decreases proportionally with the altitude (temperature and pressure). The evaluation of the lifting force is only referred to $1 \mathrm{~m}^{3}$ of lifting gas and does not include the bag and lines of the balloon.

The balloon was modelled as a sphere, which contains lifting gas sufficient to equalize, more or less, $W_{\text {Tо }}$. The main mission parameters to be defined are altitude (pressure altitude (pressure altitude is the reading of an altimeter when adjusted to the standard MSL (mean sea level) atmospheric pressure of $1013.25 \mathrm{mbar}$ (29.98 inches of mercury); it does not correspond to the actual elevation): PA, temperature $T$ ), gas density, and air density. Typical PA values in the range 6-20 m $(20-65 \mathrm{ft})$ and air temperature of $288 \mathrm{~K}\left(15^{\circ} \mathrm{C}\right)$, reasonably constant in the selected altitude range, were considered. The density-pressure-temperature nomogram (Figure 6) can be used to determine the inflation requirements of the balloon.

The blue dashed line in Figure 6 shows the initial inflation in the selected operational conditions and determines a balloon gas density of $0.168 \mathrm{~kg} / \mathrm{m}^{3}$. The design volume $V_{D}$ of the spherical balloon and the weight of the inflation gas, $W_{\mathrm{He}}$, were computed through use of the perfect gas law, giving

$$
\begin{aligned}
V_{D} & =\frac{W_{\mathrm{TO}}}{\left(1-\left(p_{g} / p_{\text {air }}\right)\left(R_{\text {air }} / R_{g}\right)\right)\left(g p_{\text {air }} / R_{\text {air }} T^{*}\right)}, \\
W_{\mathrm{He}} & =\rho_{g} V_{D},
\end{aligned}
$$

where $T^{*}=T_{g} / T_{\text {air }}$ and $V_{D}$ is referred to a fully inflated balloon.

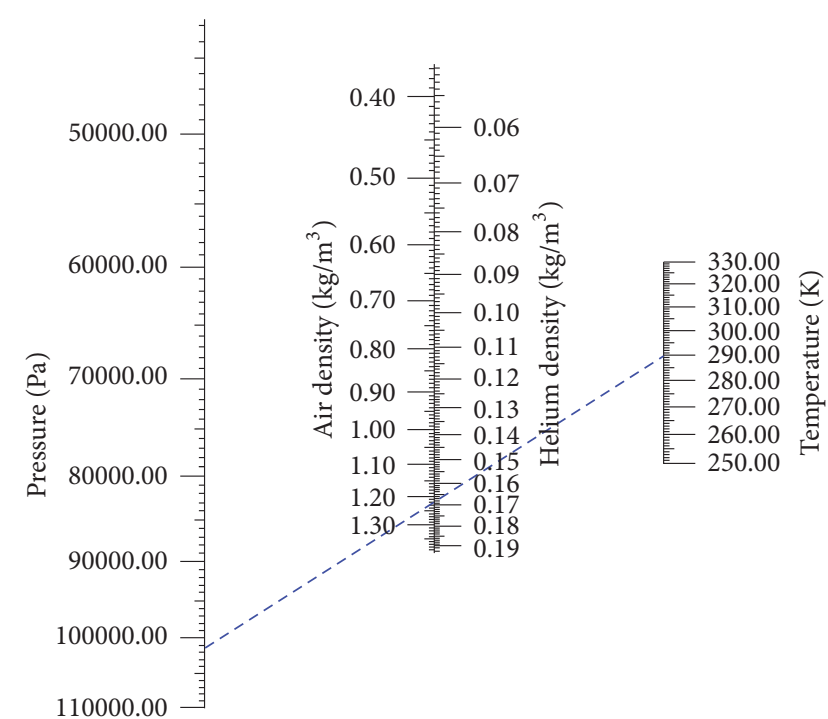

FIGURE 6: Density-pressure-temperature nomogram and initial inflation determination (dashed line).

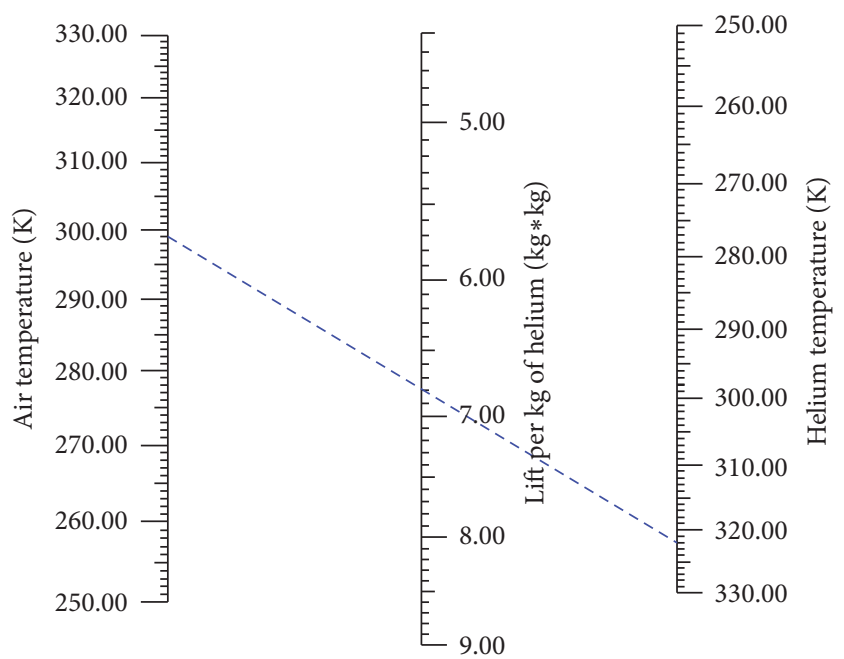

FIGURE 7: Nomogram for the expected gross static lift $\left(T_{\text {air }}=\right.$ $\left.299 \mathrm{~K}, T_{\mathrm{He}}=322 \mathrm{~K}\right)$.

Equation (7) gives the design volume (cubic feet are the preferred unit in the compressed-gas industry) required in standard conditions, $V_{\mathrm{STD}}$ :

$$
V_{\mathrm{STD}}=\frac{\rho_{g}}{\rho_{\mathrm{STD}}} \frac{W_{\mathrm{TO}}}{\left(1-\left(p_{g} / p_{\mathrm{air}}\right)\left(R_{\mathrm{air}} / R_{g}\right)\right)\left(g p_{\mathrm{air}} / R_{e} T^{*}\right)} .
$$

It is now possible to calculate the expected gross static lift $\left(L_{\text {exp }}\right)$, given by (1), considering the nomogram for initial inflation, shown in Figure 7. From the blue dashed line $L_{\text {exp }}$ is found to be $6.78 \mathrm{~kg}$ per $\mathrm{kg}$ of $\mathrm{He}$, considering the maximum expected temperatures: $T_{\text {air }}=299 \mathrm{~K}\left(\approx 27^{\circ} \mathrm{C}\right)$ and $T_{\mathrm{He}}=$ $322 \mathrm{~K}\left(\approx 49^{\circ} \mathrm{C}\right)$.

Generally, $L$ depends on atmospheric pressure and temperature, but we considered a constant pressure value, due 
to the low altitude and the small altitude range (0 to $19 \mathrm{~m})$ chosen.

The gross static lift $L$ is given by

$$
L=\frac{L_{\text {exp }} \rho_{g} W_{\text {TO }}}{\left(1-\left(p_{g} / p_{\text {air }}\right)\left(R_{\text {air }} / R_{g}\right)\right)\left(\rho_{\mathrm{STD}} g p_{\text {air }} / R_{\text {air }} T^{*}\right)} .
$$

The design volume $V_{D}$ is the main parameter determining gross static lift for a specific diameter of the balloon. Various diameters have been considered, in order to attain good efficiency $\left(L\left(V_{D}\right) /\right.$ Drag $\left.\approx 1\right)$, at low altitude and low speed.

Recalling that $W_{\text {TO }}$ is equal to $3 \mathrm{~kg}$, the balloon weight $W_{B}$ given by

$$
W_{B}=W_{\mathrm{He}}+W_{\mathrm{bag}}+W_{\text {lines }}
$$

has to be added. $W_{\mathrm{He}}$ is given by (6), and the remaining weights are a function of $V_{D}$ and the material used for the bag and the lines. In Section 4 we will show a set of diameters and the corresponding solutions.

The balloon thickness is obviously dependent on the helium pressure, which in turn depends on temperature, volume of the bag $\left(V_{D}\right)$, and number of moles of He. Using the ideal gas law and assuming operational conditions at $T=$ $15^{\circ} \mathrm{C}(288.15 \mathrm{~K})$ and $p=1031.25 \mathrm{hPa}$, the helium pressure, which must be sustained by the structure (bag), is given by

$$
p_{\mathrm{He}}=\frac{n R T}{V_{D}} .
$$

Young-Laplace law [23] can be used to derive the pressure difference $\Delta p=p_{\mathrm{He}}-p_{\text {air }}$, across the interface between air and helium, assuming a spherical balloon of radius $r$ :

$$
\Delta p=\frac{2 \tau(r)}{r}
$$

where $\tau$ is the surface tension (obviously, $\Delta p$ should be less than the maximum tension of the balloon, to avoid bursting). The material chosen for the balloon was PVC (polyvinyl chloride), whose mechanical characteristics are summarized in Table 6.

It turned out that the tension forces $\tau$ are small and the balloon pressure is very close to the atmospheric pressure. Therefore, thickness in the range $0.10-0.30 \mathrm{~mm}$ is sufficient to guarantee the necessary lift, keeping the balloon away from bursting conditions.

\section{Preliminary Results}

The test field and the atmospheric conditions are very important in order to evaluate the lifting properties of the inflation gas used for our HUAS. Experimental results were acquired considering three cases (modelling three different environmental conditions):

(i) Standard operating conditions (International Standard Atmosphere, ISA, $0 \mathrm{~km}$ mean sea level (MSL), temperature $15.0^{\circ} \mathrm{C}(288.15 \mathrm{~K})$, density $1.225 \mathrm{~kg} / \mathrm{m}^{3}$, and pressure $1013.25 \mathrm{hPa}$ )
TABLE 6: PVC mechanical characteristics.

\begin{tabular}{lccc}
\hline Property & Units & Method & Value \\
\hline Specific weight & $\mathrm{g} / \mathrm{cm}^{3}$ & ISO 1183 & 1.42 \\
Yielding tension & $\mathrm{MPa}$ & DIN EN ISO 527 & 58 \\
Elastic modulus & $\mathrm{MPa}$ & DIN EN ISO 527 & 3000 \\
Hardness SHORE D & - & ISO 868 & 82 \\
\hline
\end{tabular}

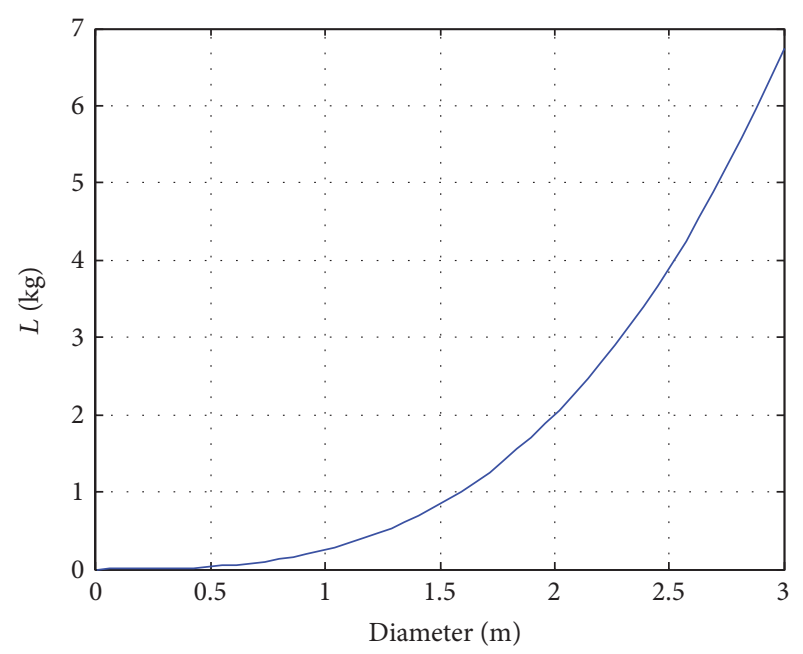

Figure 8: Gross static lift versus balloon diameter.

(ii) Complex scenario (ISA $+25^{\circ} \mathrm{C}$ and ISA $-25^{\circ} \mathrm{C}$ )

In this paper only the temperature variation of air and of the inflation gas is considered. Relative humidity is not taken into account due to its negligible influence on the lifting properties. Air speed has been set equal to 0 (hovering condition). No variation on the payload mass was taken into account, since there is no fuel consumption. Table 7 summarizes the expected operating conditions and the helium expected gross static lift in the standard operating conditions.

Helium density and the expected gross static lift are quite similar (see Figures 6 and 7) and were considered constant. On average, we have a gross static lift (from (8)) of $2.84 \mathrm{~kg}$. In this case, one $\mathrm{kg}$ of $\mathrm{He}$ is sufficient to lift the UAS and sensors $\left(W_{\text {eq }}+W_{\text {batt }}+W_{p}\right)$.

Using a spherical configuration, the total gross static lift becomes a function of the balloon diameter, as shown in Figure 8 (see also (6)).

Figure 9 shows the dependence of the gas weight (to be added to obtain $W_{\text {TO }}$ ) on the balloon diameter.

In order to analyse the effects of temperature on the static lift, we performed several tests in different conditions, namely, ISA $-25^{\circ} \mathrm{C}$ and ISA $+25^{\circ} \mathrm{C}$, that is, $-10^{\circ} \mathrm{C}$ and $+40^{\circ} \mathrm{C}$, as operational boundaries in which the HUAS is expected to work.

By using the nomograms of Figures 6 and 7 and (8), an estimate of the expected helium gross static lift is shown in Table 8 and Figures 10 and 11 .

We found little differences with respect to the standard condition, concluding that the balloon can provide the required lift even in complex scenarios, since its inflation 
TABLE 7: Lifting properties of He in standard (ISA) operating conditions.

\begin{tabular}{lcccc}
\hline $\begin{array}{l}\text { Pressure } \\
\text { altitude }[\mathrm{m}]\end{array}$ & $\begin{array}{c}\text { Air or helium } \\
\text { temperature } \\
{\left[{ }^{\circ} \mathrm{C}\right]}\end{array}$ & $\begin{array}{c}\text { Helium expected } \\
\text { gross static lift } \\
{[\mathrm{kg} \mathrm{per} \mathrm{kg} \mathrm{of} \mathrm{He]}]}\end{array}$ & $\begin{array}{c}\text { Helium } \\
\text { density } \\
{\left[\mathrm{kg} / \mathrm{m}^{3}\right]}\end{array}$ & $\begin{array}{c}\text { Air density } \\
{\left[\mathrm{kg} / \mathrm{m}^{3}\right]}\end{array}$ \\
\hline 7 & 17.1045 & 6.78 & 0.1681 & 0.1681 \\
10 & 17.0850 & 6.78 & 0.1681 & 1.2241 \\
13 & 17.0655 & 6.78 & 0.1682 & 1.2238 \\
16 & 17.0460 & 6.78 & 0.1682 & 1.2231 \\
19 & 17.0265 & 6.78 & 1.2227 \\
\hline
\end{tabular}

TABLE 8: Results in ISA $-25^{\circ} \mathrm{C}$ and ISA $+25^{\circ} \mathrm{C}$ operating conditions.

\begin{tabular}{lccccc}
\hline $\begin{array}{l}\text { Pressure } \\
\text { altitude } \\
{[\mathrm{m}]}\end{array}$ & $\begin{array}{c}\text { Air or helium } \\
\text { temperature } \\
{\left[{ }^{\circ} \mathrm{C}\right]}\end{array}$ & $\begin{array}{c}\text { Helium } \\
\text { expected gross } \\
\text { static lift } \\
{[\mathrm{kg} \text { per kg He] }}\end{array}$ & $\begin{array}{c}\text { Helium } \\
\text { density } \\
{\left[\mathrm{kg} / \mathrm{m}^{3}\right]}\end{array}$ & $\begin{array}{c}\text { Air } \\
\text { density } \\
{\left[\mathrm{kg} / \mathrm{m}^{3}\right]}\end{array}$ & $\begin{array}{c}\text { Gross static } \\
\text { lift }(\mathrm{see}(8)) \\
{[\mathrm{kg}]}\end{array}$ \\
\hline 7 & -10.609 & 6.23 & 0.161 & 1.17 & 2.61 \\
10 & -10.609 & 6.23 & 0.161 & 1.17 & 2.61 \\
13 & -10.608 & 6.23 & 0.161 & 1.17 & 2.61 \\
16 & -10.605 & 6.23 & 0.161 & 1.17 & 2.61 \\
19 & -10.605 & 6.23 & 0.161 & 1.17 & 2.61 \\
7 & 40.253 & 6.21 & 0.158 & 1.15 & 2.61 \\
10 & 40.248 & 6.21 & 0.158 & 1.15 & 2.61 \\
13 & 40.233 & 6.21 & 0.158 & 1.15 & 2.61 \\
16 & 40.230 & 6.21 & 0.158 & 1.15 & 2.61 \\
19 & 40.226 & 6.21 & 0.158 & 1.15 & 2.61 \\
\hline
\end{tabular}

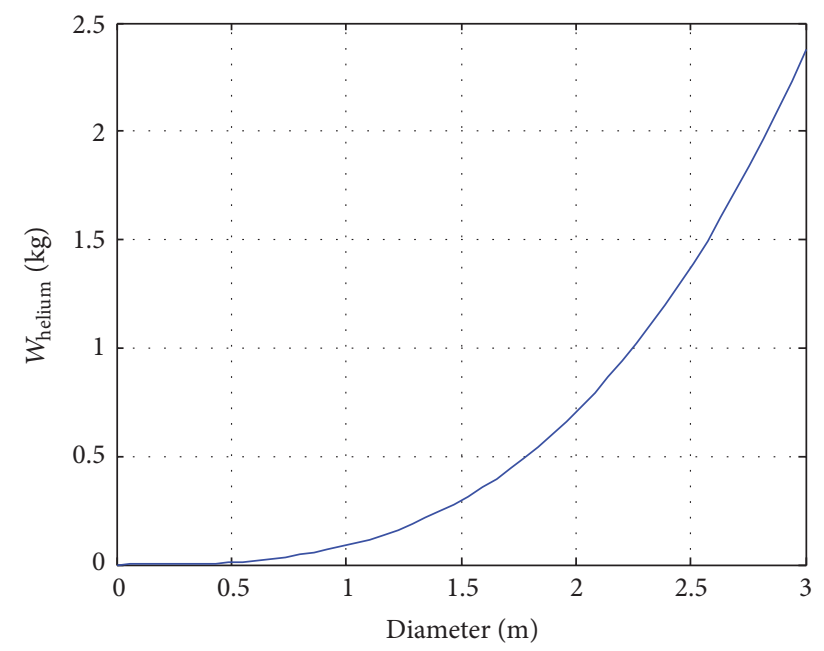

FIGURE 9: Gas weight versus balloon diameter.

requirement is not dependent on temperature in the range from -10 to $+40^{\circ} \mathrm{C}$.

The total balloon weight $W_{B}$ is estimated considering a PVC bag with thickness in the range $0.18-0.28 \mathrm{~mm}$. The weight of the link lines is reasonably constant within the considered thickness range.

A diameter of 2.7 meters provides full $W_{\text {TO }}$ equivalence (bag and lines included, see Figure 9), but in terms of control

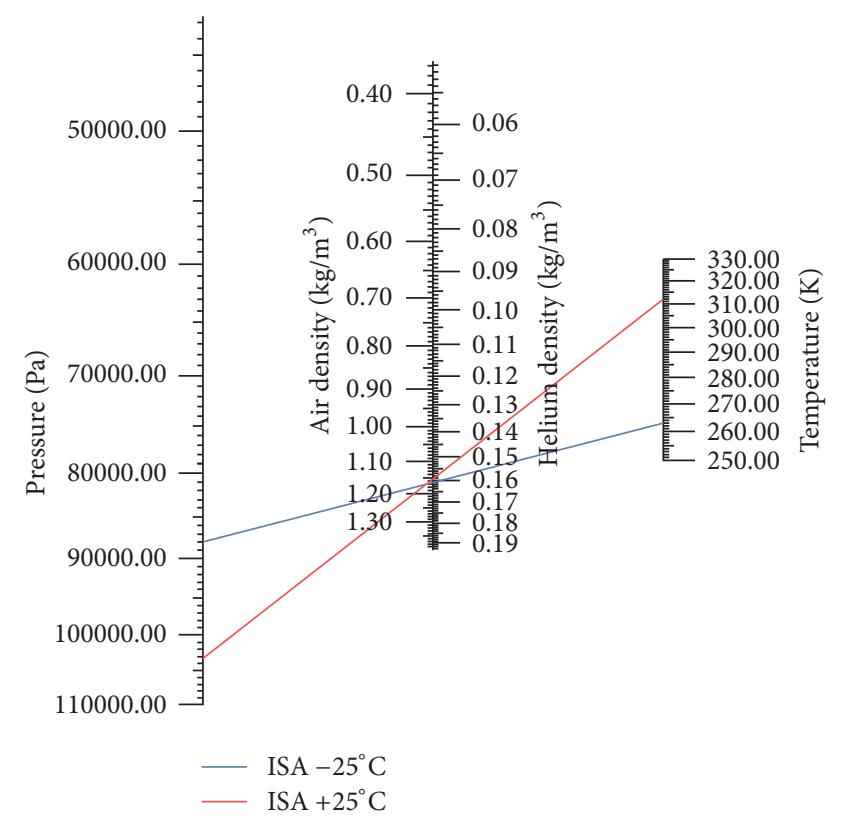

FIgUre 10: Air and helium densities in ISA $-25^{\circ} \mathrm{C}$ and ISA $+25^{\circ} \mathrm{C}$.

and manoeuvring it is a poor choice, since such a value involves high drag force, depending on body sectional area, acting opposite to the relative motion. This, in turn, involves weak manoeuvrability and control. Since our goal is to reduce 


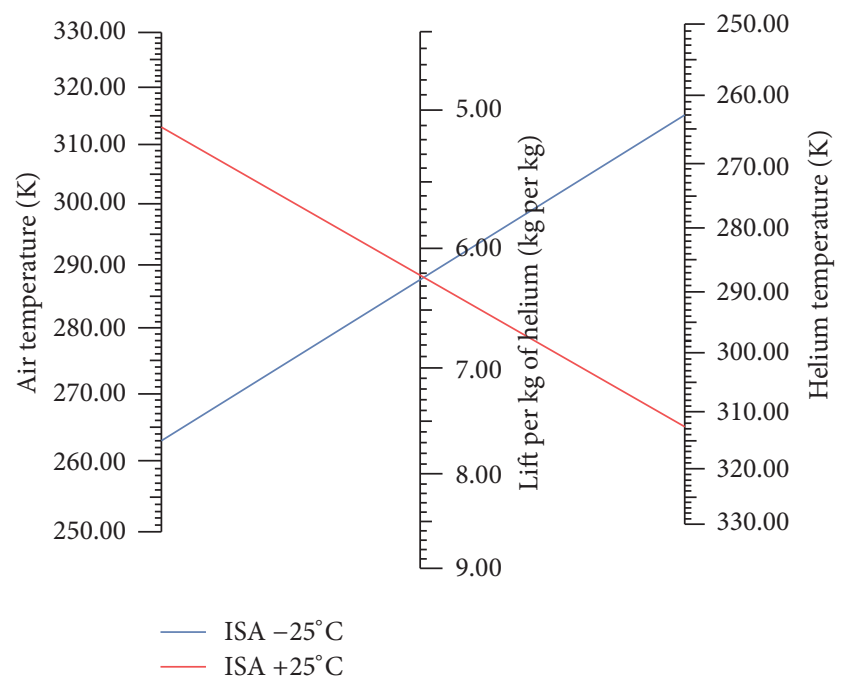

FIgURE 11: Expected static lift per $\mathrm{kg}$ of $\mathrm{He}$ in ISA $-25^{\circ} \mathrm{C}$ and ISA $+25^{\circ} \mathrm{C}$. The value (almost the same for both cases) has been found to be about $6.22 \mathrm{~kg}$ per $\mathrm{kg}$ of He.

power consumption of the rotors to increase endurance, it is not necessary to maximize the total gross lift (i.e., $L=W_{\mathrm{TO}}$ ). In this preliminary design (Figure 12 shows the relationships among design parameters), a solution with gross static lift less than $W_{\text {TO }}$ has been chosen, resulting in low diameter and low drag force, with acceptable manoeuvrability and control.

Under these hypotheses, considering the initial inflation parameters, it is be possible to estimate gross static lift values for a specific balloon diameter. The generated gross lift is $67 \%$ of $W_{\mathrm{TO}}$, for a 2-meter balloon diameter: in this condition the HUAS is able to come back to the ground by its own gravity. During landing and hovering, the lift provided by the balloon and quadcopter can help to get the desired hovering height; so, the total lift is less than the HUAS weight (sensors included). If the propeller speed decreases, the HUAS can land due to its own weight.

Table 9 shows increased performance of the HUAS in the hovering phase, with respect to the standard UAS (without balloon), showing 50\% and 40\% improvement on the hovering time with the $4000 \mathrm{mAh}$ and $1800 \mathrm{mAh} \mathrm{LiPo}$ battery pack used, respectively. No significant change in takeoff and landing time was observed.

\section{Conclusions and Further Work}

This paper reported the main phases of the conceptual design of a low-cost (less than $2 \mathrm{k} €$ ), electrically powered hybrid UAS (quadrotor + airship). We investigated the HUAS capability of extended cruise endurance by analysing the design drivers affecting the craft flight time. With respect to conventional electric-motor/battery powered UAS, in which increasing endurance requires heavier batteries, with a consequent weight increment, we propose a solution that increases endurance by using a balloon, resulting in a favourable endurance/weight ratio.
TABLE 9: HUAS versus UAS endurance.

\begin{tabular}{lcccc}
\hline & \multicolumn{2}{c}{ UAS } & \multicolumn{2}{c}{ HUAS } \\
& $\begin{array}{c}\text { Take-off and } \\
\text { landing }\end{array}$ & Hovering & $\begin{array}{c}\text { Take-off and } \\
\text { landing }\end{array}$ & Hovering \\
\hline $4000 \mathrm{mAh}$ & $<5 \mathrm{~min}$ & $\approx 40 \mathrm{~min}$ & $<5 \mathrm{~min}$ & $\approx 60 \mathrm{~min}$ \\
$1800 \mathrm{mAh}$ & $<5 \mathrm{~min}$ & $\approx 15 \mathrm{~min}$ & $<5 \mathrm{~min}$ & $\approx 25 \mathrm{~min}$ \\
\hline
\end{tabular}

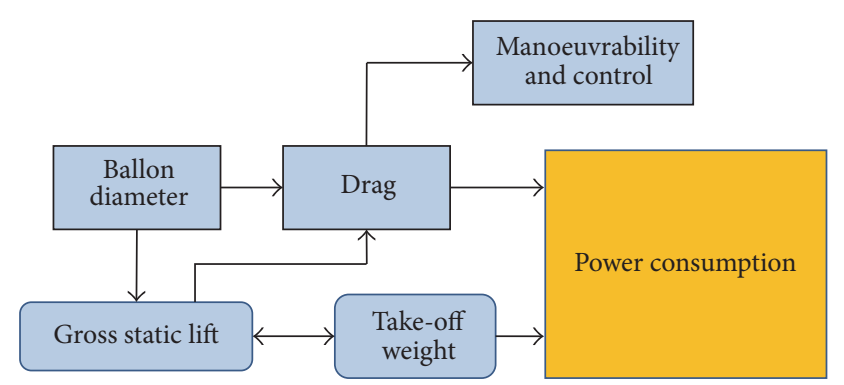

FIGURE 12: Relationships among design parameters.

The installation of a balloon with a diameter of about 2 meters provided significant increase in flight time, as demonstrated in test missions developed in situ (urban traffic monitoring scenario). As shown in Table 9, the HUAS endurance (with $1800 \mathrm{mAh}$ LiPo battery) increased by $50 \%$. The effect of temperature changes on the static lift provided by the balloon (inflated with helium) has been found to be negligible, providing an average value of $2.84 \mathrm{~kg}$ lift $(27.8 \mathrm{~N})$ per $\mathrm{kg}$ of $\mathrm{He}$.

Further investigations will focus on stability and control problems $[3,22]$ of the HUAS, caused by wind flow (e.g., vertical/horizontal gusts $[24,25])$, critical scenarios in takeoff and landing (e.g., sloped terrain, obstacles), and pendulum effects during left/right turning, which make trajectory tracking and attitude stabilization challenging tasks [26]. These effects mainly depend on nonlinearities like coupling between the quadrotor and the balloon. Nonlinear techniques [27] are currently under study, together with a structural modification of the craft. The main theoretical aspects to be analysed in further developments will concern optimal control techniques for the following critical issues:

(1) Stabilization and attitude control during the hovering phase and capability of tracking straight-line trajectories $[28,29]$

(2) Transition between flight modes and operation near ground (especially in take-off and landing missions, where the HUAS is supposed to smoothly reach a desired hovering height or to descend from initial height to $0 \mathrm{~m}$ )

(3) Collision avoidance

As a preliminary step, two additional propellers (Figure 13) will be added to the existing configuration in order to provide thrust for flight direction changing. To remove the nonlinearity introduced by pendulum moments, the tether lines will be reduced, obtaining a final UAS + balloon single structure shown in Figure 14. Preliminary simulations and 


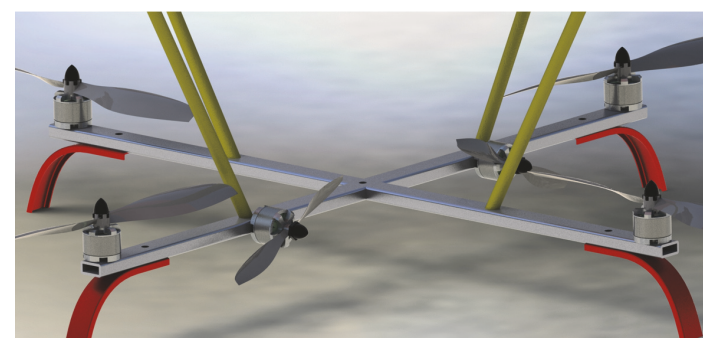

FIGURE 13: Latest HUAS configuration, with directional propellers.

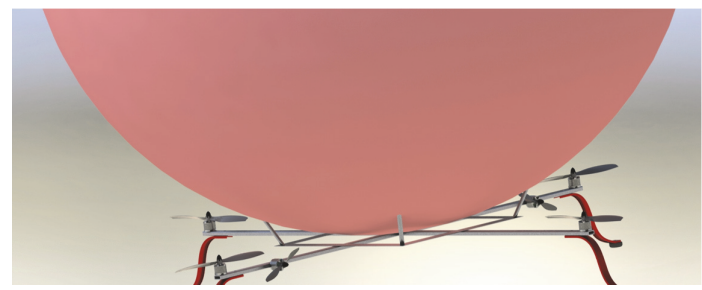

FIGURE 14: Newest configuration to reduce nonlinearities.

dynamic studies confirm improved HUAS stability, allowing us to tune the mechanical design for optimal control sensitivity and disturbance rejection.

Another issue to be explored in further work is the purity of the lifting gas (it is not easy to find $100 \%$ pure $\mathrm{He}$ ), which could impair the gas performance during the mission. The impact of nonpure helium on the lifting properties is currently under examination.

\section{Nomenclature}

$\begin{array}{ll}\rho_{g} \text { and } \rho_{\text {air }}: & \text { Gas density and air density }\left(\mathrm{kgm}^{-3}\right) \\ g: & \text { Gravitational acceleration }\left(9.8066 \mathrm{~ms}^{-2}\right) \\ L: & \text { Static lift }(\mathrm{kg}) \\ p, p_{g} \text {, and } p_{\text {air }}: & \text { Pressure, gas pressure, and air pressure } \\ & (\mathrm{Pa}) \\ R: & \text { Perfect gas constant } \\ & \left(8.314 \mathrm{~Pa} \mathrm{~m}^{3} \mathrm{~mol}^{-1} \mathrm{~K}^{-1}\right) \\ T_{g} \text { and } T_{\text {air }}: & \text { Gas temperature and air temperature }(\mathrm{K}) \\ V_{D}: & \text { Balloon design volume }\left(\mathrm{m}^{3}\right) \\ V_{g}: & \text { Gas volume }\left(\mathrm{m}^{3}\right) \\ W \text { and } W_{\mathrm{TO}}: & \text { Weight and take-off gross weight }(\mathrm{kg}) .\end{array}$

\section{Disclosure}

This research is a thesis topic in Flight Mechanics/Dynamics and Aeronautical Systems at the Department of Science and Technology of the University of Naples "Parthenope," with a team of many students studying different HUAS-related issues and developing and proposing possible solutions (under the authors' supervision).

\section{Conflicts of Interest}

The authors Umberto Papa, Giuseppe Del Core, and Salvatore Ponte declare that there are no conflicts of interest regarding the publication of this paper.

\section{Acknowledgments}

The balloon structure and the integration of electronic subsystems were performed at the Laboratory of Flight Dynamics of the University of Naples "Parthenope," Italy.

\section{References}

[1] T. Villa, F. Gonzalez, B. Miljievic, Z. D. Ristovski, and L. Morawska, "An overview of small unmanned aerial vehicles for air quality measurements: Present applications and future prospectives," Sensors (Switzerland), vol. 16, no. 7, article no. 1072, 2016.

[2] Y. Inoue, S. Morinaga, and A. Tomita, "A blimp-based remote sensing system for low-altitude monitoring of plant variables: A preliminary experiment for agricultural and ecological applications," International Journal of Remote Sensing, vol. 21, no. 2, pp. 379-385, 2000.

[3] S. N. Ghazbi, Y. Aghli, M. Alimohammadi, and A. A. Akbari, "Quadrotors unmanned aerial vehicles: a review," International Journal on Smart Sensing and Intelligent Systems, vol. 9, no. 1, pp. 309-333, 2016.

[4] Z. Sarris, "Survey of UAV applications in civil markets," in Proceedings of the 9th IEEE Mediterranean Conference on Control and Automation, Technical University of Crete, Corfu, Greece, June 2001.

[5] R. Austin, "Unmanned Aircraft Systems: UAVS Design, Development and Deployment," Unmanned Aircraft Systems: UAVS Design, Development and Deployment, 2010.

[6] Office of the Secretary of Defense, Unmanned Aircraft Systems Roadmap: 2005-2030., Office of the Secretary of Defense, Washington, DC, USA, 2005.

[7] H. Eisenbeiss, "A mini unmanned aerial vehicle (UAV): system overview and image acquisition," in Proceedings of the International Workshop on Processing and Visualization using HighResolution Imagery, Institute for Geodesy and Photogrammetry, ETH-Hoenggerberg, Zurich, Switzerland, 2004.

[8] K. Nonami, F. Kendoul, S. Suzuki, W. Wang, and D. Nakazawa, "Autonomous flying robots: Unmanned aerial vehicles and micro aerial vehicles," Autonomous Flying Robots: Unmanned Aerial Vehicles and Micro Aerial Vehicles, pp. 1-329, 2010.

[9] X. Liu and R. Zhu, "Endurance optimization for micro air vehicles," Acta Aeronautica et Astronautica Sinica, vol. 29, no. 1, 2008.

[10] O. Gur and A. Rosen, "Optimizing electric propulsion systems for unmanned aerial vehicles," Journal of Aircraft, vol. 46, no. 4, pp. 1340-1353, 2009.

[11] J. Y. Hung and L. F. Gonzalez, "On parallel hybrid-electric propulsion system for unmanned aerial vehicles," Progress in Aerospace Sciences, vol. 51, pp. 1-17, 2012.

[12] T. Chang and H. Yu, "Improving Electric Powered UAVs' Endurance by Incorporating Battery Dumping Concept," in Proceedings of the Asia-Pacific International Symposium on Aerospace Technology, APISAT 2014, pp. 168-179, chn, September 2014.

[13] N. Lapeña-Rey, J. A. Blanco, E. Ferreyra, J. L. Lemus, S. Pereira, and E. Serrot, "A fuel cell powered unmanned aerial vehicle for low altitude surveillance missions," International Journal of Hydrogen Energy, vol. 42, no. 10, pp. 6926-6940, 2017.

[14] X. Z. Gao, Z. X. Hou, Z. Guo, J. X. Liu, and X. Q. Chen, "Energy management strategy for solar-powered high-altitude 
long-endurance aircraft," Energy Conversion and Management, vol. 70, pp. 20-30, 2013.

[15] G. Ferrarese, F. Giulietti, and G. Avanzini, "Modeling and simulation of a quad-tilt rotor aircraft," in Proceedings of the 2nd IFAC Workshop on Research, Education and Development of Unmanned Aerial Systems (RED-UAS), pp. 64-70, Compiegne, France, November 2013.

[16] Y. Wang, S. Le, and Z. Fan, "A new type of rotor + airbag hybrid unmanned aerial vehicle," International Journal of Energy Science, vol. 3, no. 3, pp. 183-187, 2013.

[17] CONRAD, 2016 http://www.conrad.com/ce/en/product/208000/ QUADROCOPTER-450-ARF-35-MHz.

[18] U. Papa and G. Del Core, "Design and assembling of a lowcost mini UAV quadcopter system," Tech. Rep., Department of Science and Technology, University of Naples "Parthenope", Naples, Italy, 2014.

[19] U. Papa and G. Del Core, "Design of sonar sensor model for safe landing of an UAV," in Proceedings of the 2nd IEEE International Workshop on Metrology for Aerospace, MetroAeroSpace 2015, pp. 346-350, Benevento, Italy, June 2015.

[20] H. Timmis, "Robot integration engineering a GPS module with the arduino," in Practical Arduino Engineering, chapter 5, pp. 97-131, Springer Science+ Business Media, New York, NY, USA, 2011.

[21] W. W. Carson and P. A. Peters, Gross Static Lifting Capacity of Logging Balloons, USDA Forest Service Research Note, 1971.

[22] S. A. Barton, "Stability analysis of an inflatable vacuum chamber," Journal of Applied Mechanics, Transactions ASME, vol. 75, no. 4, pp. 0410101-0410108, 2008.

[23] G. K. Batchelor, An Introduction to Fluid Dynamics, Cambridge University Press, 1967.

[24] War Department, “Technical Manual of Airship Aerodynamics," TM 1-320, US Government Printing Office, Washington, DC, USA, 1941.

[25] L. T. Redd, R. M. Bennett, and S. R. Bland, "Experimental and analytical determination of stability parameters for a balloon tethered in a wind," NASA TN D-7222, 1973.

[26] G. Cai, B. M. Chen, K. Peng, M. Dong, and T. H. Lee, "Modeling and control system design for a UAV helicopter," in Proceedings of the 14th Mediterranean Conference on Control and Automation, pp. 600-606, Ancona, Italy, 2006.

[27] I. Fantoni and R. Lozano, Non-linear Control for Underactuated Mechanical Systems, Springer-Verlag, London, UK, 2002.

[28] N. G. Shakev, A. V. Topalov, O. Kaynak, and K. B. Shiev, "Comparative results on stabilization of the quad-rotor rotorcraft using bounded feedback controllers," Journal of Intelligent \& Robotic Systems, vol. 65, no. 1, pp. 389-408, 2012.

[29] F. Kendoul, D. Lara, I. Fantoni-Coichot, and R. Lozano, "Realtime nonlinear embedded control for an autonomous quadrotor helicopter," Journal of Guidance, Control, and Dynamics, vol. 30, no. 4, pp. 1049-1061, 2007. 


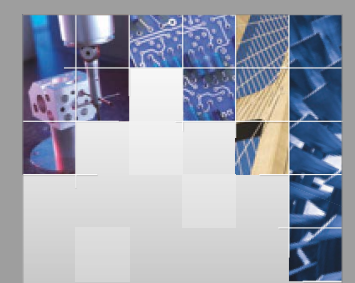

\section{Enfincering}
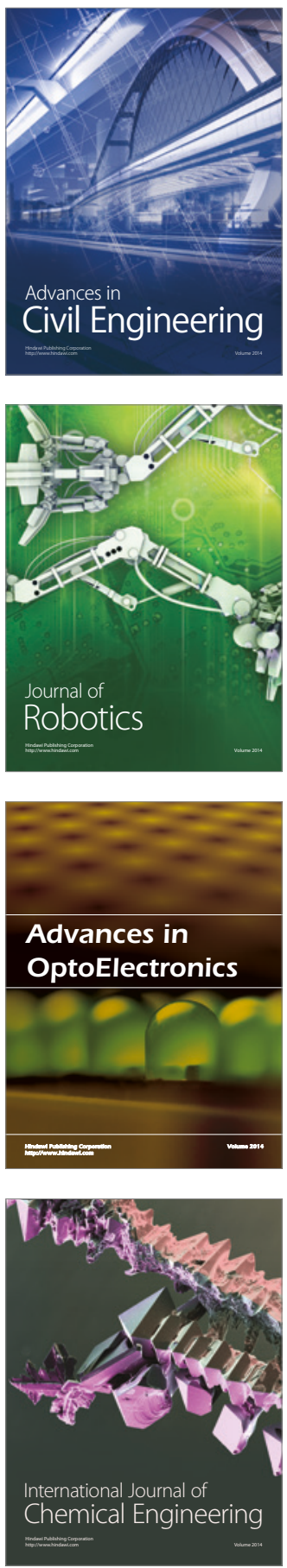

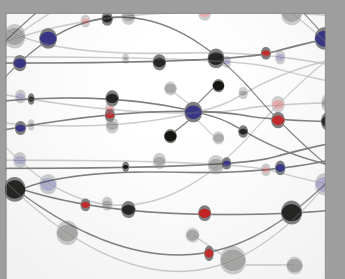

The Scientific World Journal

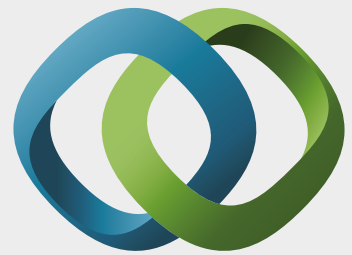

\section{Hindawi}

Submit your manuscripts at

https://www.hindawi.com
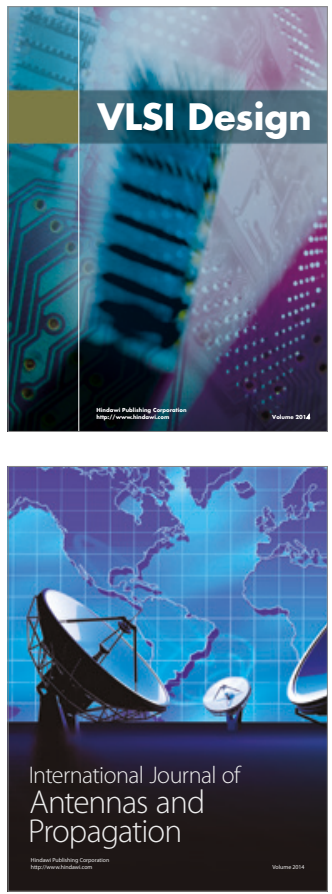

\section{Rotating}

Machinery
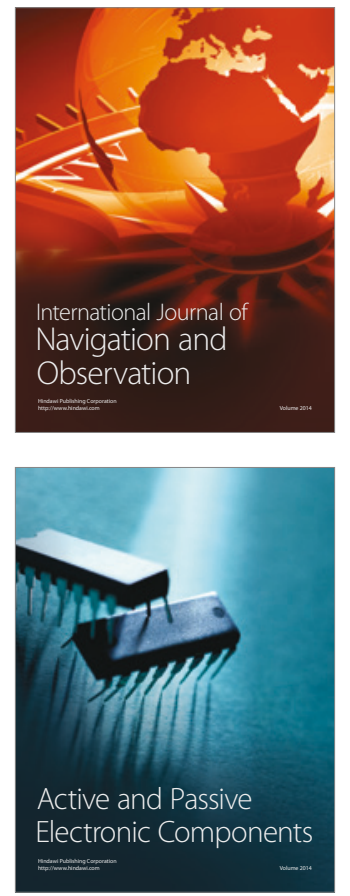
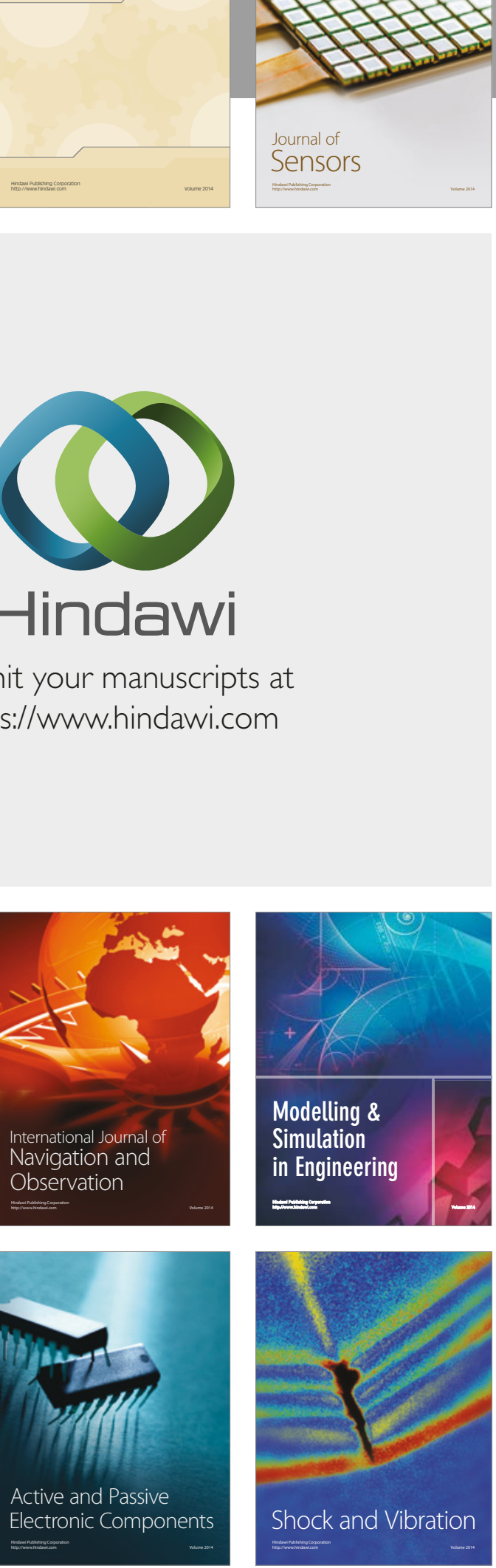
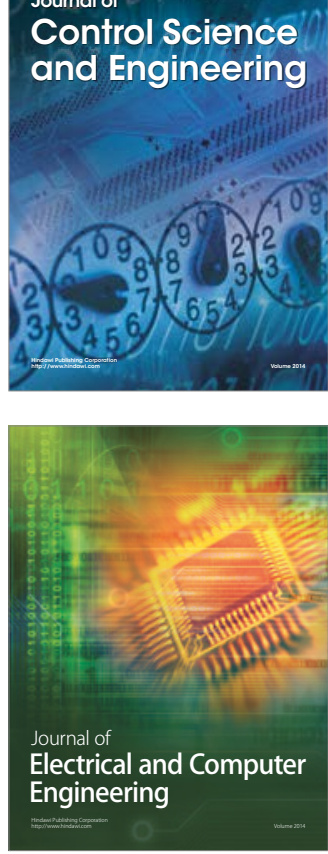

Distributed

Journal of

Control Science

and Engineering
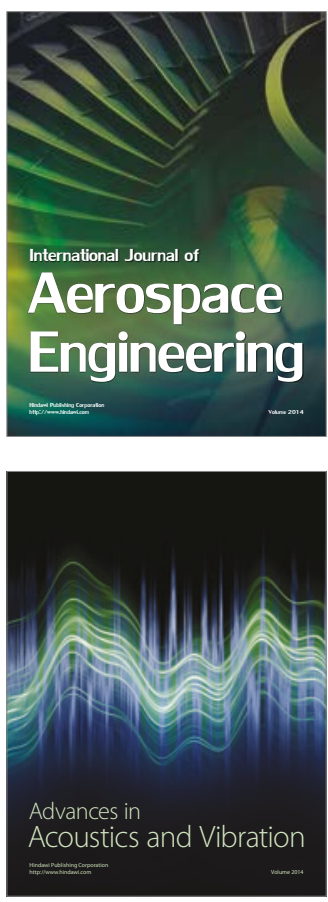

Sensor Networks 